\title{
Türkiye’de Fisher Hipotezinin Fourier Yaklaşımı ile İncelenmesi
}

Mustafa Orhan ÖZER*

Geliş Tarihi (Received): 03.05.2019 - Kabul Tarihi (Accepted): 26.08.2019

\section{Öz}

Faiz ve enflasyon oranları arasındaki ilişki genellikle Fisher hipotezi çerçevesinde ele alınmaktadır. Fisher hipotezine göre, enflasyon oranında meydana gelen değişimler nominal faiz oranını aynı yönde etkilemektedir. Böylece reel faiz oranı enflasyon oranından etkilenmemekte ve uzun dönemde belirli bir ortalama etrafında salınım göstermektedir. Dolayısıyla Fisher hipotezinin geçerli olduğu bir ülkede, nominal faiz ve enflasyon oranları arasında uzun dönemli ilişkinin bulunması ve reel faiz oranının durağan olması beklenmektedir. Bu çalışmada, Türkiye'de 1988-2019 döneminde Fisher hipotezinin geçerliliği Fourier yaklaşımı ile incelenmiştir. Bu çerçevede, nominal faiz ve enflasyon oranlarına Fourier birim kök testi uygulanmış, değişkenlerin düzeylerinde birim köklü, birinci farkı alındıklarında ise durağan oldukları tespit edilmiştir. Daha sonra, değişkenler arasındaki uzun dönemli ilişkinin varlığını sınamak amacıyla Fourier eşbütünleşme testi uygulanmış ve enflasyon oranından nominal faiz oranına doğru olmak üzere tek yönlü uzun dönemli ilişki bulunmuştur. Son olarak, reel faiz oranının durağanllğı yine Fourier birim kök testi ile incelenmiş ve düzeyde durağan olduğu görülmüştür. $\mathrm{Bu}$ durum, eşbütünleşme testinden elde edilen bulguları desteklemektedir. Ulaşılan sonuçlar Türkiye'de Fisher hipotezinin geçerli olduğunu kanıtlamaktadır.

Anahtar Kelimeler: Fisher Hipotezi, Fourier Yaklaşımı, Faiz Oranı, Enflasyon Oranı.

\footnotetext{
* Doktora Öğrencisi, İstanbul Üniversitesi, Sosyal Bilimler Enstitüsü, İktisat Anabilim Dalı, orcid.org/0000-0002-
} 3222-9913, mustafaorhanozer@gmail.com 


\title{
Analysing of Fisher Hypothesis in Turkey with Fourier Approach
}

\begin{abstract}
The relationship between interest and inflation rates is generally considered within the framework of the Fisher hypothesis. According to the Fisher hypothesis, changes in the inflation rate affect the nominal interest rate in the same direction. In this way the real interest rate is not affected by the inflation rate and shows a long-term oscillation around a certain average. Therefore, in a country where the Fisher hypothesis is valid, it is expected that there will be a long-term relationship between the nominal interest and inflation rates and the real interest rate will be stationary. In this study, validity of Fisher hypothesis is investigated in Turkey for the period between 1988-2019 with Fourier approach. In this framework, Fourier unit root test is applied to nominal interest and inflation rates. While these variables are not stationary at the levels, them are stationary at the first differences. Then, Fourier cointegration test is run to examine the existence long-run relationship between the variables and has been found that unilateral long-run relationship from inflation rate to nominal interest rate. Finally, stationarity of real interest rate is examined with Fourier unit root test and it is understood that the variable is stationary at level. This supports the findings obtained from the cointegration test. Results achieved show that Fisher hypothesis is valid in Turkey.
\end{abstract}

Keywords: Fisher Hypothesis, Fourier Approach, Interest Rate, Inflation Rate. 


\section{Giriş}

Fisher hipotezi, nominal faiz ve enflasyon oranlarının uzun dönemde birlikte hareket ettiğini ve nominal faiz oranının enflasyon oranından etkilendiğini ileri sürmektedir. Enflasyon oranının düşmesi durumunda borç almak isteyen bireyler nominal faiz oranı düşünceye kadar borçlanmayı ertelemektedirler. Bu durum, para piyasasında fon talebinin azalmasına ve nominal faiz oranının düşmesine neden olmaktadır. Fisher'e (1930) göre, 1861-1865 yılları arasında yaşanan Amerikan İç Savaşı ve 1895-1896 döneminde ortaya çıkan panik dalgası bu hipotezi kanıtlamaktadır (ss. 400-401). Yüksek enflasyon oranlarının görüldüğü bu dönemlerde, yapılan sözleşmeler mevcut nominal faiz oranı ile dolar üzerinden hazırlanmamış, bunun yerine altın üzerinden veya daha yüksek seviyede belirlenen nominal faiz oranı ile dolar üzerinden hazırlanmıştır.

Fisher hipotezinin denklemi şu şekilde tanımlanmaktadır (Granville ve Mallick, 2004, s. 87):

$$
1+r_{t}=\frac{1+i_{t}}{1+\pi_{t}}
$$

Burada $i_{t}$ nominal faiz oranın1, $\pi_{t}$ enflasyon oranını, $r_{t}$ reel faiz oranını göstermektedir. 1 numaralı denklemin reel faiz için çözümü aşağıdaki gibidir:

$$
r_{t}=\frac{i_{t}-\pi_{t}}{1+\pi_{t}}
$$

2 numaralı denklemde paydanın ihmal edilmesi ve reel faiz oranının sabit kabul edilmesi durumunda, nominal faiz oranı beklenen enflasyon oranı tarafindan belirlenmektedir.

$$
i_{t}=r_{t}+\pi_{t}^{e}
$$

Burada $\pi_{t}^{e}$ beklenen enflasyon oranını ifade etmektedir. 3 numaralı denkleme göre, reel faiz ve beklenen enflasyon oranlarının toplamı nominal faiz oranını vermektedir.

Fisher hipotezinin geçerli olması halinde, beklenen enflasyon oranındaki değişim ile nominal faiz oranındaki değişim eşit olmaktadır (Benazic, 2013, s. 84). Fisher hipotezinin tam geçerli olduğu böyle bir durumda reel faiz oranı sürekli sabit kalmaktadır. Nominal faiz oranındaki artışın beklenen enflasyon oranındaki artıştan daha az olması, Fisher hipotezinin geçerli ancak etkinliğinin zayıf olduğu göstermektedir. Bu durumda yıllar itibariyle reel faiz oranında dalgalanmaların görülmesi doğaldır. Yine de reel faiz oranının düzeyde durağan olması, Fisher hipotezinin geçerliliğine dair önemli bir gösterge olarak kabul edilmektedir (Bolatoğlu, 2006, s. 9). 
Fisher hipotezinin geçerli olduğu bir ülkede, beklenen enflasyon oranında meydana gelen değişiklikler reel faiz oranı üzerinde etkisiz veya oldukça sınırlı düzeyde etkili olmaktadır. Para politikasının finansal piyasalar üzerinde etki yaratma eğiliminde olduğu göz önünde bulundurulduğunda Fisher hipotezinin geçerliliği, belirli bir dönemde uygulanan para politikalarının etkinliği açısından önemli bir gösterge olarak kabul edilmektedir (Ito, 2009, ss. 1030-1031). Dolayısıyla Fisher hipotezinin geçerli olduğu durumda uygulanan para politikalarının etkisiz olduğu veya oldukça sınırlı bir etkiye sahip olduğu söylenebilir.

Bu çalışmanın amacı Türkiye'de Fisher hipotezinin geçerliliğini sınamaktır. Literatürde yer alan çoğu çalışmadan farklı olarak Fourier yaklaşımından faydalanılmıştır. Fourier fonksiyonlarına dayanan birim kök ve eşbütünleşme testleri, incelenen değişkenlerin etkisi altında bulunduğu yapısal kırılmaların sayısı, konumu ve formundan bağımsız olarak daima güçlü sonuçlar üretmektedirler (Yılancı, 2017, ss. 56-58). Songur (2018), çalışmasında Türkiye'de 2002:Q1-2018-Q1 dönemine ait üç aylık verilerle faiz ve enflasyon oranları arasındaki ilişkiyi Fourier yaklaşımını kullanarak incelemiş ve Fisher hipotezinin geçersiz olduğu bulgusuna ulaşmıştır. Bu çalışmada ise 1988:10-2019:01 dönemine ait aylık veriler kullanılmaktadır. Böylece daha geniş bir zaman aralığı incelenmekte ve daha fazla gözlem sayısı ile çalışılmaktadır. Ayrıca enflasyon oranının nominal faiz oranı üzerindeki etkisinin yanı sıra nominal faiz oranının enflasyon oranı üzerindeki etkisi de araştırılmaktadır.

Çalışma dört bölümden oluşmaktadır. Birinci bölümde geniş kapsamlı bir literatür taraması bulunmaktadır. Burada çeşitli ülkeler ve Türkiye için Fisher hipotezinin geçerliliğini araştıran çok sayıda çalışmanın ulaştığı sonuçlara yer verilmektedir. İkinci bölümde kullanılan ekonometrik yöntem ele alınmaktadır. Burada öncelikle değişkenlerin durağanlıklarını sınamak amacıyla tercih edilen Fourier KPSS birim kök testi, daha sonra ise değişkenler arasındaki uzun dönemli ilişkiyi araştırmak amacıyla kullanılan Fourier Shin eşbütünleşme testi açıklanmaktadır. Üçüncü bölümde, kullanılan veri seti hakkında bilgi verildikten sonra ampirik bulgular belirtilmiştir. Dördüncü ve son bölümde ise çalışmanın sonuçları değerlendirilmektedir.

\section{Literatür Taraması}

Literatüre bakıldığında Fisher hipotezi üzerine çok sayıda çalışma yapıldığı görülmektedir. Bu çalışmaların büyük bir kısmı Fisher hipotezinin geçerli olduğunu ortaya koyarken, bazıları geçersiz olduğu sonucuna ulaşmıştır. Çeşitli ülkeler için Fisher hipotezinin geçerliliğini sınayan çalışmalar şu şekilde özetlenebilir: 
Hasan (1999), çalışmasında Pakistan'da 1957:Q1-1992:Q2 dönemine ait üç aylık verilerle faiz ve enflasyon oranları arasındaki ilişkiyi Engle-Granger eşbütünleşme testi ile araştırmıştır. Analiz sonucunda enflasyonun uzun dönemde faiz oranını pozitif yönde etkilediği ancak faiz oranındaki değişimin enflasyondaki değişimden daha az olduğu tespit edilmiştir. Dolayısıyla Fisher hipotezinin kısmen geçerli olduğu ve yüksek enflasyon dönemlerinde reel faiz oranının azaldığı bulgusuna ulaşılmıştır.

Granville ve Mallick (2004), çalışmalarında İngiltere'de 1900-2000 dönemine ait y1llık verilerle faiz ve enflasyon oranları arasındaki ilişkiyi Johansen eşbütünleşme testi ile incelemişlerdir. Elde edilen bulgular Fisher hipotezinin geçerli olduğuna işaret etmektedir.

Dutt ve Ghosh (2005), çalışmalarında Belçika, Fransa, Almanya, İtalya ve İsveç olmak üzere 5 Avrupa ülkesinde 1960:01-2004:04 dönemine ait aylık verilerle faiz ve enflasyon oranları arasındaki ilişkiyi Hansen-Seo eşbütünleşme testi ile araştırmışlardır. Analiz sonucunda genel olarak Fisher hipotezinin geçerli olduğu bulgusuna ulaşmışlardır.

Nusair (2008), çalışmasında Endonezya, Kore, Malezya, Filipinler, Singapur ve Tayland olmak üzere 6 Asya ülkesinde 1978:Q1-2005:Q1 dönemine ait üç aylık verilerle faiz ve enflasyon oranları arasındaki ilişkiyi Gregory-Hansen eşbütünleşme testi ile analiz etmiştir. Çalışmada Fisher hipotezinin 4 ülkede geçerli, 2 ülkede ise geçersiz olduğu sonucuna ulaşılmıştır.

Ito (2009), çalışmasında Japonya'da 1987:01-2006:06 dönemine ait aylık verilerle faiz ve enflasyon oranları arasındaki ilişkiyi Engle-Granger eşbütünleşme testi ile araştırmıştır. Çalışmada söz konusu dönem, para politikası rejimlerine göre üç alt döneme ayrılmış ve her dönem için Fisher hipotezinin geçerliliği analiz edilmiştir. Analiz sonucunda sadece 1987:011991:06 dönemi için Fisher hipotezinin geçerli olduğu bulgusuna ulaşılmıştır. Söz konusu alt dönemde uygulanan sıkı para politikalarının bu sonucun ortaya çıkmasında etkili olduğu düşünülmektedir.

Toyoshima ve Hamori (2011), çalışmalarında ABD, İngiltere ve Japonya'da 1990:012010:12 dönemine ait aylık verilerle faiz ve enflasyon oranları arasındaki ilişkiyi panel eşbütünleşme testi ile araştırmışlardır. Analiz sonucunda bu ülkelerde Fisher hipotezinin geçerli olduğu bulgusuna ulaşmışlardır.

Jareno ve Tolentino (2013), çalışmalarında 27 Avrupa ülkesinde 1997:01-2012:06 dönemine ait aylık verilerle faiz ve enflasyon oranları arasındaki ilişkiyi Sıradan En Küçük Kareler yöntemi ile incelemişlerdir. Analiz sonucunda birçok ülkede Fisher hipotezinin geçerli 
ancak etkinliğinin zayıf olduğu, 2008-2012 kriz döneminde Fisher hipotezinin daha güçlü olduğu, 1997-2007 genişleme döneminde ise Fisher hipotezinin geçersiz olduğu bulgularına ulaşmışlardır.

Ito (2016), çalışmasında İsveç’te 1993:01-2015:02 dönemine ait aylık verilerle faiz ve enflasyon oranları arasındaki ilişkiyi Engle-Granger eşbütünleşme testi ile analiz etmiştir. Analiz sonucunda Fisher hipotezinin 2, 3, 4, 5 ve 7 ylllık vadeli faiz oranları için geçerli, 10 yıllık vadeli faiz oranı için ise geçersiz olduğu bulgusuna ulaşmıştır.

Aralarında Türkiye'nin de bulunduğu çok sayıda ülke için Fisher hipotezinin geçerliliğini sınayan çalışmalar şu şekilde özetlenebilir:

Bozoklu ve Yılancı (2011), çalışmalarında aralarında Türkiye'nin de bulunduğu 15 gelişmekte olan ülkede 1996:01-2009:12 dönemine ait aylık verilerle Fisher hipotezinin geçerliliğini panel birim kök testleriyle araştırmışlardır. Analiz sonucunda reel faiz oranının durağan olduğu ve dolayısıyla Fisher hipotezinin geçerli olduğu bulgusuna ulaşmışlardır.

Büberkökü (2014), çalışmasında aralarında Türkiye'nin de bulunduğu 7 gelişmekte olan ülkede 2003:01-2013:04 12 dönemine ait aylık verilerle faiz ve enflasyon oranları arasındaki ilişkiyi Kao ve Pedroni panel eşbütünleşme testleri ile analiz etmişlerdir. Analiz sonucunda Fisher hipotezinin geçerli ancak etkinliğinin zayıf olduğu bulgusuna ulaşmışlardır.

Kim, Lin, Hsieh ve Suen (2016), çalışmalarında aralarında Türkiye'nin de bulunduğu 30 gelişmiş ve gelişmekte olan ülkede 1998:Q1-2012:Q4 dönemine ait aylık verilerle faiz ve enflasyon oranları arasındaki ilişkiyi doğrusal olmayan panel veri analizi ile araştırmışlardır. Analiz sonucunda enflasyonun faiz oranı üzerinde etkili olduğu bulunmuş, ancak Fisher hipotezinin geçerliliğine dair herhangi bir kanıt elde edilememiştir.

Küçükaksoy ve Akalın (2017), çalışmalarında aralarında Türkiye'nin de bulunduğu 18 OECD ülkesinde 1995:Q1-2014:Q4 dönemine ait üç aylık verilerle faiz ve enflasyon oranlar1 arasındaki ilişkiyi Dinamik panel veri analizi ile analiz etmişlerdir. Analiz sonucunda OECD ülkelerinin ekonomik yapıları farklı olduğu için her ülkede faiz ve enflasyon oranlarının birbirini farklı derecelerde etkilediği bulgusuna ulaşmışlardır.

Tıraşoğlu (2018), çalışmasında aralarında Türkiye'nin de bulunduğu MINT ülkelerinde 1990:01-2017:12 dönemine ait aylık verilerle faiz ve enflasyon oranları arasındaki ilişkiyi Eşik Değerli ADL eşbütünleşme testi ile araştırmıştır. Ulaşılan sonuçlar söz konusu ülkelerde Fisher hipotezinin geçerli olduğunu ortaya koymaktadır. 
Sağlam (2018), çalışmasında aralarında Türkiye'nin de bulunduğu gelişmekte olan 11 ülkede 1995-2016 dönemine ait yıllık verilerle faiz ve enflasyon oranları arasındaki ilişkiyi Kademeli kırılmalı panel birim kök testi ile analiz etmiştir. Analiz sonucunda Endonezya ve Filipinler hariç diğer 9 ülkede Fisher hipotezinin geçerli olduğu tespit edilmiştir.

Fisher hipotezinin Türkiye'de geçerliliğini sınayan çalışmaların geniş bir özeti ise şu şekildedir:

Çakmak, Aksu ve Başar (2002), çalışmalarında Türkiye'de 1989:01-2001:07 dönemine ait aylık verilerle faiz ve enflasyon oranları arasındaki ilişkiyi Engle-Granger eşbütünleşme testi ve VAR model ile araştırmışlardır. Uygulanan eşbütünleşme testinin sonucuna göre Türkiye'de Fisher hipotezinin geçerli olmadığı ortaya konulmuştur. Yapılan VAR analizi ise enflasyonun faiz oranları üzerinde etkili olduğunu göstermiştir.

Turgutlu (2004), çalışmasında Türkiye'de 1978:Q4-2003:Q4 dönemine ait üç aylık verilerle faiz ve enflasyon oranları arasındaki ilişkiyi Engle-Granger ve parçalı eşbütünleşme testleri ile analiz etmiştir. Analiz sonucunda Fisher hipotezinin Engle-Granger eşbütünleşme testine göre geçersiz, parçalı eşbütünleşme testine göre ise geçerli olduğu tespit edilmiştir.

Bolatoğlu (2006), çalışmasında Türkiye'de 1990:01-2005:04 dönemine ait aylık verilerle faiz ve enflasyon oranları arasındaki ilişkiyi Engle-Granger ve Johansen eşbütünleşme testleri ile araştırmıştır. Yapılan çalışma Türkiye'de Fisher etkisinin geçerli olduğu ortaya koymuştur.

Şimşek ve Kadılar (2006), çalışmalarında Türkiye'de 1987:Q1-2004:Q4 dönemine ait üç aylık verilerle faiz ve enflasyon oranları arasındaki ilişkiyi ARDL sınır testi yaklaşımı ile araştırmışlardır. Analiz sonucunda Fisher hipotezinin varlığına dair bulgulara ulaşılmıştır.

Y1lancı (2009), çalışmasında Türkiye'de 1989:01-2008:01 dönemine ait üç aylık verilerle faiz ve enflasyon oranları arasındaki ilişkiyi Engle-Granger ve doğrusal olmayan eşbütünleşme testleri ile ele almıştır. Analiz sonucunda Türkiye'de Fisher hipotezinin geçersiz olduğu bulgusuna ulaşılmıştır.

Bayat (2011), çalışmasında Türkiye'de 2002:01-2011:05 dönemine ait aylık verilerle alternatif faiz oranları ve enflasyon arasındaki ilişkiyi Seo tarafından geliştirilen doğrusal olmayan eşbütünleşme testi ile analiz etmiştir. Çalışma sonucunda Fisher hipotezinin geçersiz olduğu yönünde bulgular elde edilmiştir. 
İncekara, Demez ve Ustaoğlu (2012), çalışmalarında Türkiye'de 1989:Q1-2011:Q4 dönemine ait üç aylık verilerle faiz ve enflasyon oranları arasındaki ilişkiyi Johansen eşbütünleşme testi ile araştırmışlardır. Analiz sonucunda Fisher hipotezinin geçerli olduğu sonucuna ulaşılmıştır.

Arısoy (2013), çalışmasında Türkiye'de 1987:Q1-2010:Q3 dönemine ait üç aylık verilerle faiz ve enflasyon oranları arasındaki ilişkiyi Gregory-Hansen eşbütünleşme testi ile araştırmışlar, değişkenler arasında uzun dönemli ilşki olduğunu ortaya çıkarmışlardır. Ayrıca Tam modifiye En Küçük Kareler yöntemi ve Kanonik eşbütünleşme regresyonu kullanılarak uzun dönem katsayıları tahmin edilmiştir. Ulaşılan sonuçlar Fisher hipotezinin geçerli ancak etkinliğinin zayıf olduğunu göstermektedir.

Mercan (2013), çalışmasında Türkiye'de 1992:01-2013:01 dönemine ait aylık verilerle faiz ve enflasyon oranları arasındaki ilişkiyi ARDL sınır testi yaklaşımı ile araştırmıştır. Analiz sonucunda Fisher etkisinin geçerli olduğu ancak etkinliğinin zayıf olduğu tespit edilmiştir.

Atgür ve Altay (2015), çalışmalarında 2004:01-2013:12 dönemine ait aylık verilerle faiz ve enflasyon oranları arasındaki ilişkiyi Johansen, Lütkepohl-Saikkonen eşbütünleşme testleri ve Dinamik En Küçük Kareler yöntemi ile analiz etmişlerdir. Yapılan çalışma Türkiye'de Fisher etkisinin geçerli olduğuna işaret etmektedir.

Kanca, Üzümcü ve Deniz (2015), çalışmalarında 1980-2013 dönemine ait yıllık verilerle faiz ve enflasyon oranları arasındaki ilişkiyi araştırmışlardır. Yapılan çalışmada Fisher hipotezinin geçerli olduğu sonucuna ulaşılmıştır.

Köksel ve Destek (2015), çalışmalarında Türkiye'de 2002:01-2014:12 dönemine ait aylık verilerle faiz ve enflasyon oranları arasındaki ilişkiyi Maki yapısal kırılmalı eşbütünleşme testi ile araştırmışlardır. Analiz sonucunda Türkiye'de Fisher hipotezinin geçerli olduğu bulunmuştur.

Akıncı ve Yılmaz (2016), çalışmalarında Türkiye'de 1980-2012 dönemine ait yıllık verilerle faiz ve enflasyon oranları arasındaki ilişkiyi Johansen-Juselius eşbütünleşme, Granger nedensellik testleri ve Dinamik En Küçük Kareler yöntemi ile analiz etmişlerdir. Analiz sonucunda Fisher etkisinin geçerli olduğu yönünde bulgular elde etmişlerdir.

Doğan, Eroğlu ve Değer (2016), çalışmalarında Türkiye'de 2003:01-2015:02 dönemine ait aylık verilerle faiz ve enflasyon oranları arasındaki ilişkiyi Johansen eşbütünleşme ve Granger nedensellik testleri ile araştırmışlardır. Analiz sonucunda Fisher etkisinin geçerli olduğu bulgusuna ulaşmışlardır. 
Öruç (2016), çalışmasında Türkiye'de 1988:Q1-2014:Q4 dönemine ait üç aylık verilerle faiz ve enflasyon oranları arasındaki ilişkiyi Engle-Granger ve Johansen eşbütünleşme testleri ile araştırmıştır. Çalışmada Fisher hipotezinin geçerli olduğu sonucuna ulaşılmıştır.

Güriş, Güriş ve Ün (2016), çalışmalarında Türkiye'de 2003:01-2012:12 dönemine ait aylık verilerle faiz ve enflasyon oranları arasındaki ilişkiyi ADL eşbütünleşme testi ile araştırmışlardır. Yapılan çalışma Türkiye'de Fisher hipotezinin geçerliliğini ortaya koymaktadir.

Lebe ve Özalp (2016), çalışmalarında 1970:01-2014:01 dönemine ait aylık verilerle alternatf faiz oranları ve enflasyon oranı arasındaki ilişskiyi ARDL sınır testi yaklaşımı ile araştırmışlardır. Analiz sonucunda reeskont ve mevduat faiz oranlarıyla karşılaştırıldığında para politikası faiz oranının enflasyon üzerinde daha etkili olduğu bulgusuna ulaşmışlardır.

Taşar, Aççı ve Bayat (2016), çalışmalarında Türkiye'de 2003:01-2016:04 dönemine ait aylık verilerle faiz ve enflasyon oranları arasındaki ilişkiyi bootsrap yöntemine dayanan nedensellik testi ile ele almışlardır. Analiz sonucunda faiz oranının enflasyon üzerinde pozitif şoklar üzerinden geçerli, negatif şoklar üzerinden ise geçersiz olduğu bulgusuna ulaşmışlardır.

Tunalı ve Erönal (2016), çalışmalarında Türkiye'de 2003:01-2014:02 dönemine ait aylık verilerle faiz ve enflasyon oranları arasındaki ilişkiyi Gregory-Hansen eşbütünleşme testi ile araştırmışlardır. Analiz sonucunda Fisher hipotezinin uzun dönemde geçerli, kısa dönemde ise geçersiz olduğu bulgusuna ulaşmışlardır.

Alper (2017), çalışmasında Türkiye'de 1973-2016 dönemine ait yıllık verilerle faiz ve enflasyon oranları arasındaki ilişkiyi Bayer ve Hanck eşbütünleşme testi ile araştırmış, değişkenler arasında uzun dönemli ilişki olduğunu tespit etmiştir. Ayrıca Tam Modifiye ve Dinamik En Küçük Kareler yöntemleri kullanılarak Fisher hipotezinin gücü sınanmıştır. Analiz sonucunda hipotezin geçerli ancak etkinliğinin zayıf olduğu bulgusuna ulaşılmıştır.

Başar ve Karakuş (2017), çalışmalarında Türkiye'de 2004:12-2016:12 dönemine ait aylık verilerle faiz oranları ile enflasyon arasındaki ilişkiyi Johansen eşbütünleşme ve VECM Granger nedensellik testleri ile ele almışlardır. Ulaşılan sonuçlar, Fisher hipotezinin geçerli olduğuna işaret etmektedir.

Çinko (2017), çalışmasında Türkiye'de 2003:01-2017:02 dönemine ait aylık verilerle faiz ve enflasyon oranları arasındaki ilişkiyi ARDL sınır testi yaklaşımı ile incelemiştir. Çalışmanın sonucu Türkiye'de Fisher hipotezinin geçerli olduğunu göstermektedir. 
Doğan, Afsal ve Örün (2018), çalışmalarında Türkiye'de 2002:01-2018:02 dönemine ait aylık verilerle faiz ve enflasyon oranları arasındaki ilişkiyi doğrusal olmayan Granger nedensellik testi ile analiz etmişlerdir. Analiz sonucunda Fisher hipotezinin geçerli olduğu bulgusuna ulaşmışlardır.

Pınar ve Erdal (2018), çalışmalarında Türkiye'de 2006:01-2016:12 dönemine ait aylık verilerle alternatif faiz oranları ile enflasyon arasındaki ilişkiyi Johansen eşbütünleşme testi ile araştırmışlardır. Çalışma sonucunda, kullanılan bütün değişkenler için de uzun dönemde Fisher hipotezinin geçerli olduğu anlaşılmıştır.

Songur (2018), çalışmasında Türkiye'de 2002:Q1-2018:Q1 dönemine ait üç aylık verilerle alternatif faiz ve enflasyon oranları arasındaki ilişkiyi Fourier Shin eşbütünleşme testi ile analiz etmiştir. Çalışmada Fisher hipotezinin geçerli olmadığ 1 sonucuna ulaşılmıştır.

\section{Ekonometrik Yöntem}

Bu çalışmada Fisher hipotezi Fourier yaklaşımı çerçevesinde ele alınmaktadır. Fourier fonksiyonlar periyodik $y_{t}$ serisinin trigonometrik terimlerinin toplamı olarak tanımlanmaktadır (Destek ve Okumuş, 2016, s. 77). Becker, Enders ve Lee (2006) Fourier fonksiyonlarına dayanan ilk birim kök testini geliştirmişlerdir. Daha sonra Christopoulos ve Ledesma (2010), Christopoulos ve Ledesma (2011), Enders ve Lee (2012) ve Omay (2015) Fourier fonksiyonlarına dayanan çeşitli birim kök testleri önermişlerdir. Tsong, Lee, Tsai ve Hu (2016) ise Fourier fonksiyonlarına dayanan ilk eşbütünleşme testini geliştirmişlerdir. Banerjee, Arcabic ve Lee (2017) yine Fourier fonksiyonlarına dayanan farklı bir eşbütünleşme testini önermişlerdir. Bu çalışmada, değişkenlerin durağanlık durumlarını araştırmak amacıyla Becker vd. (2006) tarafından geliştirilen Fourier KPSS birim kök testi, değişkenler arasındaki uzun dönemli ilişkiyi araştırmak amacıyla Tsong vd. (2016) tarafından geliştirilen Fourier Shin eşbütünleşme testi uygulanmaktadır.

\subsection{Fourier KPSS Birim Kök Testi}

Becker vd. (2006) tarafından geliştirilen Fourier KPSS birim kök testintinde 4 ve 5 numaralı denklemlerde yer alan veri yaratma süreci dikkate alınmaktadır:

$$
\begin{aligned}
& y_{t}=X_{t}^{\prime} \beta+Z_{t}^{\prime} \gamma+r_{t}+\varepsilon_{t} \\
& r_{t}=r_{t-1}+u_{t},
\end{aligned}
$$


Burada $\varepsilon_{t}$ hata terimini, $u_{t}$ ise $\sigma_{u}^{2}$ varyans ile bağımsız ve özdeş dağılan hata terimini ifade etmektedir. $y_{t}$ serisinin düzeyde durağanlık süreci için $X_{t}=[1]$, trend durağanlık süreci için $X_{t}=[1, t]^{\prime}$ eşitlikleri kullanılmaktadır. Deterministik terimdeki kırılmayı yakalamak amacıyla tercih edilen $Z_{t}, 6$ numaralı denklemde görülmektedir:

$$
Z_{t}=\left[\sin \left(\frac{2 \pi k t}{T}\right), \cos \left(\frac{2 \pi k t}{T}\right)\right]^{\prime}
$$

Burada k frekans değerini ve $\mathrm{T}$ örneklem büyüklüğünü temsil etmektedir. $\sigma_{u}^{2}=0$ temel hipotezi altında 4 numaralı denklemde tanımlanan süreç durağan olmaktadır. $Z_{t}$ için yapılacak tercih, Fourier genişlemesinin mutlak entegre fonksiyonları istenilen herhangi bir kesinlik derecesine yaklaştırabilme kapasitesine bağlı olmaktadır (Becker vd., 2006, s. 383).

$$
\begin{aligned}
& y_{t}=\alpha+\gamma_{1} \sin \left(\frac{2 \pi k t}{T}\right)+\gamma_{2} \cos \left(\frac{2 \pi k t}{T}\right)+e_{t} \\
& y_{t}=\alpha+\beta_{t}+\gamma_{1} \sin \left(\frac{2 \pi k t}{T}\right)+\gamma_{2} \cos \left(\frac{2 \pi k t}{T}\right)+e_{t}
\end{aligned}
$$

7 veya 8 numaralı denklemlerden birisi tahmin edilerek kalıntı değerleri elde edilmektedir. Test istatistiğini ise 9 numaralı denklem ile elde etmek mümkündür:

$$
\begin{aligned}
& \tau_{\mu}(k) \text { ya da } \tau_{\tau}(k)=\frac{1}{T^{2}} \frac{\sum_{t=1}^{T} \widetilde{S_{t}}(k)^{2}}{\widetilde{\sigma}^{2}} \\
& \tilde{S}_{t}(k)=\sum_{j=1}^{T} \widetilde{e_{J}}
\end{aligned}
$$

Burada $\tilde{e}_{j}, 7$ ya da 8 numaralı denklemlerin birinden elde edilmiş olan sıradan en küçük kareler kalıntılarını göstermektedir. KPSS birim kök testinde olduğu gibi, $\tilde{\sigma}^{2}$ uzun dönem varyansının parametrik olmayan bir tahmini, $l$ parçalı parçalı gecikme parametresi ve $w_{j}$ $(j=1,2,3, \ldots, l)$ ağırlıklar dizisi seçilerek 11 numaralı denklemi elde etmek mümkündür:

$$
\tilde{\sigma}^{2}=\tilde{\gamma}_{0}+2 \sum w_{j} \tilde{\gamma}_{j}
$$

Burada $\tilde{\gamma}_{j} 7$ ya da 8 numaralı denklemlerin birinden elde edilmiş olan kalıntıların $j$. Örneklem otokorelasyonunu ifade etmektedir. En küçük kalıntı kareler toplamını (Min KKT) veren $\mathrm{k}$ değeri, optimum $\mathrm{k}$ değeri olarak tanımlanmakta ve test aşamasında bu değer tercih edilmektedir.

Veri yaratma sürecinde doğrusal olmayan trend bulunmaması durumunda, geleneksel KPSS birim kök testi Fourier KPSS birim kök testinden daha güçlü sonuçlar vermektedir. Dolayısıyla 12 numaralı denklemde yer alan ve doğrusal olmayan trendin bulunmadığını ifade 
eden temel hipotezin, 13 numaralı denklemde verilen $F$ testi ile sınanması büyük önem taşımaktadır (Becker vd., 2006, ss. 390-391).

$$
\begin{aligned}
& H_{0}: \gamma_{1}=\gamma_{2}=0 \\
& F_{i}(k)=\frac{\left(S S R_{0}-S S R_{1}(k)\right) / 2}{S S R_{1}(k) /(T-q)}, \quad i=\mu, \tau
\end{aligned}
$$

Burada $S S R_{1}(k) 7$ ya da 8 numaralı denklemlerin birinden elde edilmiş olan KKT’yi, $q$ bağımsız değişken sayısını, $S S R_{0}$ trigonometrik terimler olmaksızın denklemden elde edilen KKT'yi belirtmektedir.

Fourier KPSS birim kök testinde hesaplanan değer Becker vd. (2006) tarafından tablolaştırılmış olan kritik değerden küçük olduğunda, durağanlık durumunu ifade eden temel hipotez reddedilememektedir. Hesaplanan değer kritik değerden büyük olduğunda ise temel hipotez reddedilmekte ve değişkenin birim köklü olduğu kabul edilmektedir. Trigonometrik terimlerin anlamlılığını sınamak amacıyla kullanılan F testinde ise belirli sınırlamaya gidilmiştir. F testi, değiş̧kenlerin durağan olmaması durumunda hatalı sonuçlar verebildiği için yalnızca değişkenlerin durağan olması halinde kullanılmaktadır (Becker vd., 2006, s. 391). F testinde temel hipotezin reddedilmesi durumunda ise Fourier KPSS testi yerine geleneksel KPSS birim kök testi uygulanmaktadır (Y1lanc1, 2017, s. 57).

\subsection{Fourier Shin Eşbütünleşme Testi}

Tsong vd. (2016) tarafından geliştirilen Fourier Shin eşbütünleşme testinde 14 numaralı denklemde yer alan model dikkate alınmaktadır:

$$
y_{t}=d_{t}+x_{t}^{\prime} \beta+\eta_{t}, \quad \eta_{t}=\gamma_{t}+v_{1 t}, \quad \gamma_{t}=\gamma_{t-1}+u_{t}, \quad x_{t}=x_{t-1}+v_{2 t}
$$

Burada $u_{t}(t=1, \ldots, T)$ sıfir ortalama ve $\sigma_{u}^{2}$ varyans ile bağımsız ve özdeş dağılan hata terimini temsil etmektedir. Dolayısıyla $\gamma_{t}$ sıfır ortalamayla $\left(\gamma_{t}=0\right)$ rassal yürüyüş sürecini ifade etmektedir. $\gamma_{t}$ ve $x_{t}$ ise düzeylerinde birim köklüyken, birinci farkı alındığında durağan hale gelmektedirler (Tsong vd., 2016, s. 1087).

$d_{t}$ modelin sabit terimli $(m=0)$ veya sabit terimli ve trendli $(m=1)$ olmas durumunda sırasıyla 15 ve 16 numaralı denklemlerdeki gibi ifade edilmektedir (Y1lanc1, 2017, s. 58):

$$
\begin{aligned}
& d_{t}=\delta_{t}+f_{t}, \quad m=0 \\
& d_{t}=\delta_{t}+\delta_{1} t+f_{t}, \quad m=1
\end{aligned}
$$


$f_{t}, 17$ numaralı denklemde görüldüğü üzere Fourier fonksiyonunu ifade etmektedir:

$$
f_{t}=\alpha_{k} \sin \left(\frac{2 \pi k t}{T}\right)+\beta_{k} \cos \left(\frac{2 \pi k t}{T}\right)
$$

Fourier Shin eşbütünleşme testine ait temel ve alternatif hipotezler ise sırasıyla 18 ve 19 numaralı denklemlerde görülmektedir:

$$
\begin{aligned}
& H_{0}: \sigma_{u}^{2}=0 \\
& H_{1}: \sigma_{u}^{2}>0
\end{aligned}
$$

Temel hipotez değişkenler arasında uzun dönemli ilişsi olduğunu, alternatif hipotez ise olmadığını ifade etmektedir. Fourier Shin eşbütünleşme testinin temel denklemi aşağıdaki gibidir:

$$
y_{t}=\delta_{0}+\alpha_{k} \sin \left(\frac{2 \pi k t}{T}\right)+\beta_{k} \cos \left(\frac{2 \pi k t}{T}\right)+x_{t}^{\prime} \beta+v_{1 t}
$$

Fourier Shin eşbütünleşme test istatistiği 21 numaralı denklem ile hesaplanmaktadır:

$$
C I_{f}^{m}=T^{-2} \widehat{\omega}_{1}^{-2} \sum_{t=1}^{T} S_{t}^{2}
$$

Fourier Shin eşbütünleşme testinde hesaplanan değer Tsong vd. (2016) tarafından tablolaştırılmış olan kritik değerden küçük olduğunda, değişkenler arasında uzun dönemli ilişki olduğunu ifade eden temel hipotez reddedilememektedir. Hesaplanan değer kritik değerden büyük olduğunda ise temel hipotez reddedilmekte ve değişkenler arasında uzun dönemli ilişki bulunmadı ̆̆ kabul edilmektedir.

\section{Veri ve Ampirik Bulgular}

Bu çalışmada, Türkiye'de 1988:10-2019:01 dönemine ait aylık verilerle nominal faiz ve enflasyon oranları arasındaki ilişki Fourier Shin eşbütünleşme testi ile analiz edilmiştir. Tsong vd. (2016) tarafından geliştirilen bu test orjinalinde yıllık verilere uygulanmıştır. Daha sonra, Yılancı (2017) ve Gazel (2018) aylık verilerle, Mike ve Kızılkaya (2019) üç aylık verilerle Fourier Shin eşbütünleşme testini kullanmış ve güvenilir sonuçlara ulaşmışlardır. Nominal faiz göstergesi olarak mevduat faiz oranı, enflasyon göstergesi olarak ise tüketici fiyat endeksi dikkate alınmıştır. Verilerin tamamı IMF’nin International Financial Statistics veritabanından elde edilmiştir. 


\section{Şekil 1: Türkiye’de Nominal faiz ve Enflasyon Oranları Arasındaki İlişki}

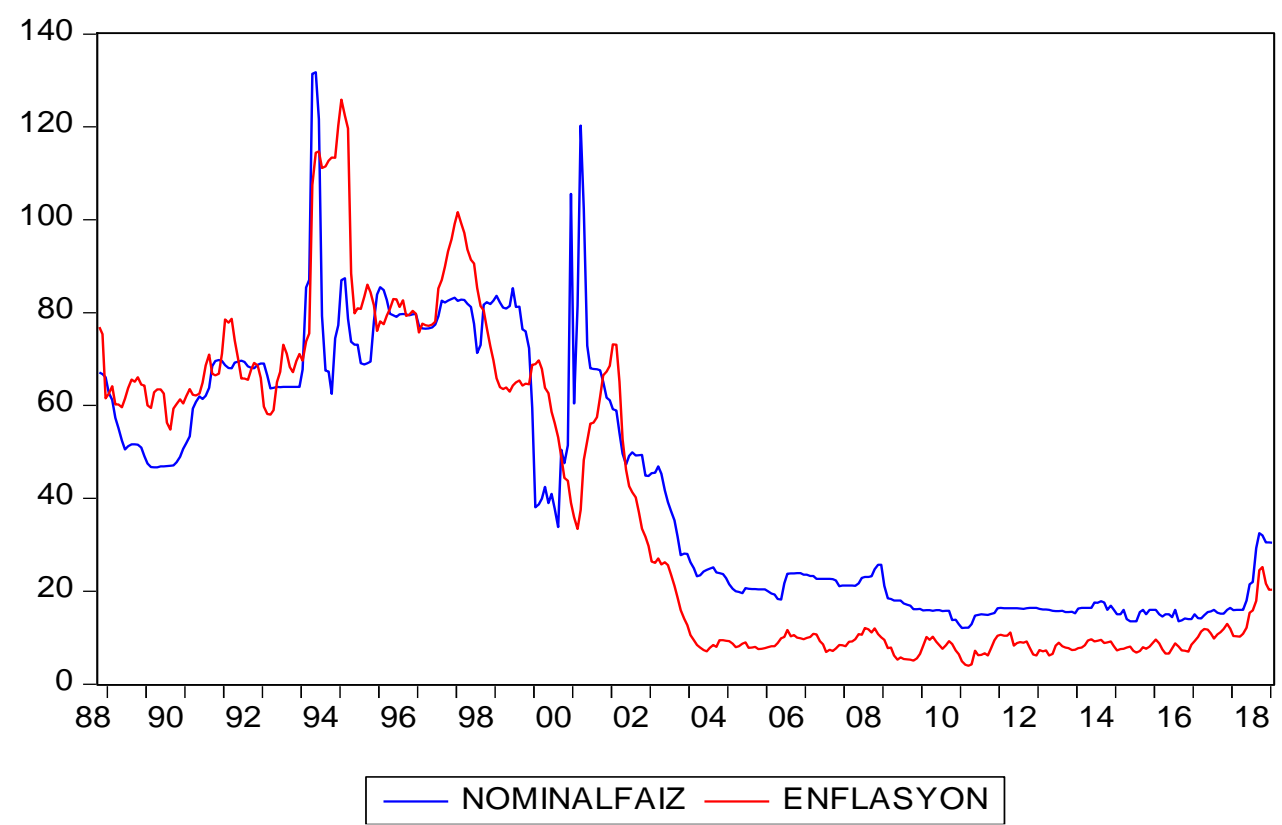

Türkiye'de 1988:10-2019:01 döneminde nominal faiz ve enflasyon oranları arasındaki ilişkiyi gösteren Şekil 1'e bakıldığında, değişkenlerin genel olarak aynı yönde hareket ettikleri görülmektedir. 1994 ve 2008 krizleri sırasında her iki değişken de eş zamanlı olarak yukarı yönde hareket etmişlerdir. 2001 krizi sırasında ise değişkenlerin kısa süreli de olsa ters yönde hareket ettikleri dikkat çekmektedir. 2001 yılından sonra değişkenlerin hızlı bir şekilde düşmeye başladığı görülmektedir. Mayıs 2002'den itibaren nominal faiz oranı daima enflasyon oranının üzerinde seyretmiş, dolayısıyla reel faiz oranı sürekli pozitif seviyede kalmıştır. Ayrıca bu dönemde değişkenlerin yapısal kırılmaların etkisi altına girmiş olmaları muhtemeldir. 1988:10-2002:04 ve 2002:05-2019:01 dönemleri karşılaştırıldığında, değişkenlerin birinci dönemde daha yüksek bir ortalama, ikinci dönemde ise daha düşük bir ortalama etrafında salınım gösterdikleri dikkat çekmektedir. Ancak Fourier KPSS birim kök ve Fourier Shin eşbütünleşme testlerinin gücü, değişkenlerin etkisi altında bulunduğu yapısal kırılmaların sayısı, konumu ve formundan etkilenmediği için, söz konusu durum bu çalışma açısından sorun teşkil etmemektedir.

Nominal faiz ve enflasyon değişkenlerine uygulanan Fourier KPSS birim kök testlerinin sonuçları aşağıdaki gibidir: 
Tablo 1: Fourier KPSS Birim Kök Testi Sonuçları

\begin{tabular}{cccccc}
\hline Değişkenler & Min KKT & $\mathbf{k}$ & $\begin{array}{c}\text { Fourier KPSS } \\
\text { Test İstatistiği }\end{array}$ & $\begin{array}{c}\text { KPSS Test } \\
\text { İstatistiği }\end{array}$ & F istatistiği \\
\hline NOMINALFAİ & 48067.34 & 1 & $0.252665(13)$ & & 820.0465 \\
ENFLASYON & 62480.32 & 1 & $0.301984(15)$ & & 974.0539 \\
FARKNOMİNALFAİZ & 14644.96 & 1 & $0.063633(34)$ & $0.108814(32)$ & 0.352476 \\
FARKENFLASYON & 4134.407 & 1 & $0.031178(1)$ & $0.088426(2)$ & 1.515821 \\
\hline
\end{tabular}

Not: Parantez içerisindeki değerler bant genişliğini ifade etmektedir. \%5 anlamlılık düzeyinde kritik değer Fourier KPSS birim kök testi için 0.1696, KPSS birim kök testi için 0.463, F testi için ise 4.651 olarak belirlenmiş̧ir.

Tablo 1'de görüldüğü üzere nominal faiz ve enflasyon değişkenlerine düzeyde Fourier KPSS testi uygulanmış, hesaplanan test istatistikleri kritik değerden büyük olduğu için değişkenlerin durağan olduğunu ifade eden temel hipotez reddedilmiştir. Düzeyde birim köklü olduğu için değişkenlerin farkı alındıktan sonra tekrar Fourier KPSS birim kök testi uygulanmış ve serilerin birinci farkı alındığında durağan hale geldikleri anlaşılmıştır. Daha sonra, trigonometrik terimlerin anlamlı olup olmadıklarını tespit etmek amacıyla $\mathrm{F}$ testi uygulanmış ve F istatistiklerinin kritik değerden daha düşük olduğu görülmüştür. Yapısal kırılmaları temsil eden sinüs ve kosinüs dalgaları trigonometrik terimleri ifade etmektedir. Trigonometrik terimlerin anlamsız olduğu durumlarda Fourier birim kök testi yerine geleneksel yöntemler kullanılmaktadır. Bu nedenle fark değişkenlere KPSS birim kök testi uygulanmış ve hesaplanan test istatistiklerinin kritik değerden küçük olduğu görülmüştür. Böylece her iki değişkenin de düzeyde durağan olmadığı, ancak birinci farkı alındığında durağan hale geldiği tespit edilmiştir. Şekil 2'de yer alan grafiklere bakıldığında Fourier fonksiyonlarının değişkenlerle oldukça uyumlu olduğu görülmektedir. 
Şekil 2: Değişkenler ve Fourier Fonksiyonları

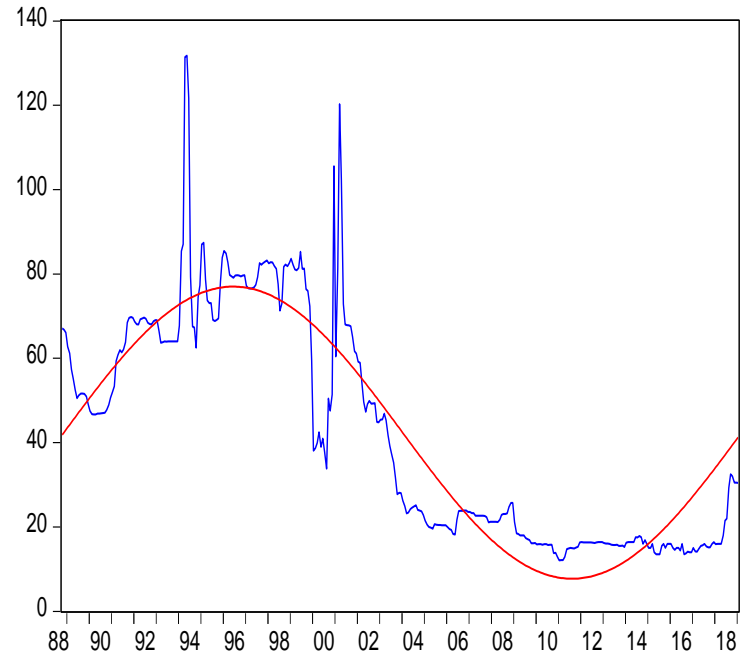

NOMINALFAİZ

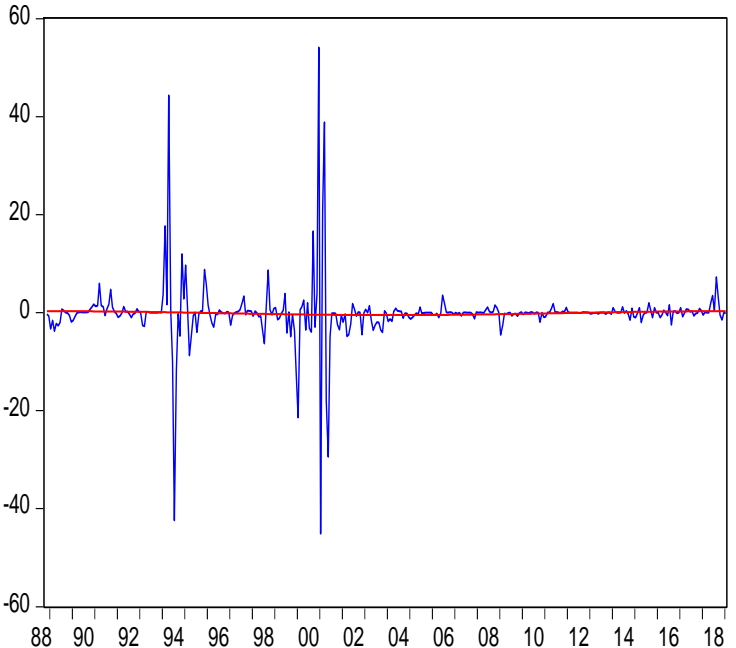

FARKNOMINALFAİZ

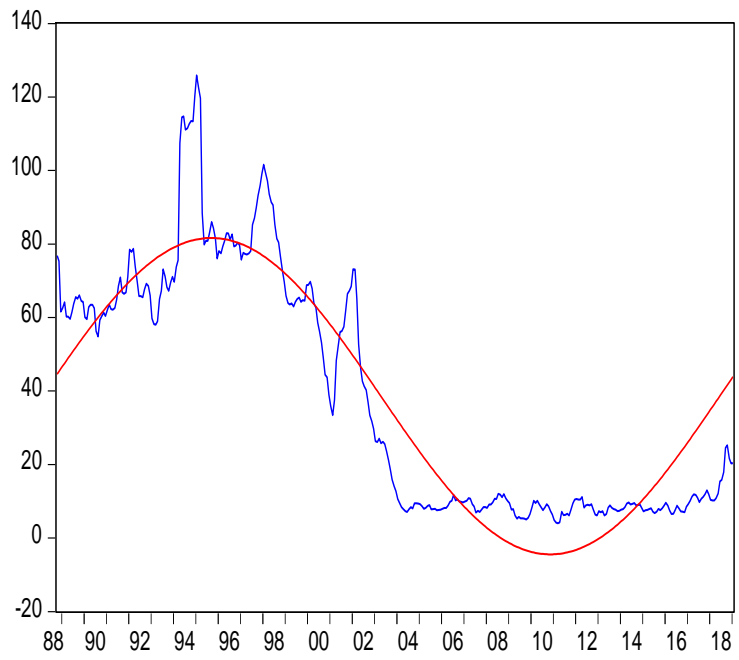

ENFLASYON

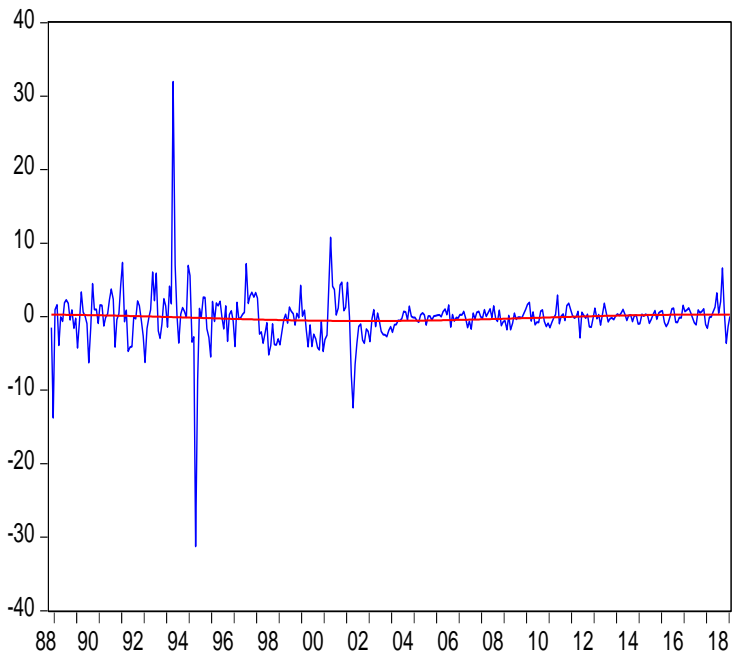

FARKENFLASYON

Değişkenler arasındaki uzun dönemli ilişkinin incelenmesi amacıyla uygulanan Fourier Shin eşbütünleşme testlerine ait sonuçlar aşağıdaki gibidir:

Tablo 2: Fourier Shin Eşbütünleşme Testi Sonuçları

\begin{tabular}{cccccccc}
\hline $\begin{array}{c}\text { Bağımlı } \\
\text { Değişken }\end{array}$ & $\begin{array}{c}\text { Bağımsız } \\
\text { Değişken }\end{array}$ & Min KKT & $\mathbf{k}$ & $\begin{array}{c}\text { Fourier Shin } \\
\text { Eşbütünleşme } \\
\text { Test İstatistiği }\end{array}$ & $\begin{array}{c}\text { Eşbütünleşme } \\
\text { Test İstatistiği }\end{array}$ & $\begin{array}{c}\text { F } \\
\text { istatistiği }\end{array}$ \\
\hline NOMINALFAIZ & ENFLASYON & 28489.46 & 1 & $0.041563(10)$ & $0.359309(12)$ & 18.95901 \\
ENFLASYON & NOMINALFAİZ & 31584.61 & 1 & $0.179916(13)$ & $0.399032(14)$ & 3.082184
\end{tabular}

Not: Parantez içerisindeki değerler bant genişliğini ifade etmektedir. Fourier Shin eşbütünleşme testi için kritik değer \%5 anlamlılık düzeyinde 0.124 olarak belirlenmiştir. 
Tablo 2'de görüldüğü üzere, nominal faiz değişkeninin bağımlı değişken olarak yer aldığg modelde, Fourier Shin eşbütünleşme test istatistiği kritik değerden küçük olduğu için değişkenler arasında uzun dönemli ilişki olduğunu ifade eden temel hipotez reddedilememektedir. Diğer taraftan, enflasyon değişkeninin bağımlı değişken olarak yer aldığı modelde, Fourier Shin eşbütünleşme test istatistiğinin kritik değerden büyük olduğu görülmektedir. Dolayısıyla değişkenler arasında karşılıklı ilişki bulunmamakta, ancak uzun dönemde enflasyondan nominal faize doğru tek yönlü ilişki bulunmaktadır. Bu durum Türkiye'de 1988:10-2019:01 döneminde Fisher hipotezinin geçerli olduğuna işaret etmektedir. Ancak bu noktada reel faiz oranının durağan olup olmaması büyük önem taşımaktadır. Bilindiği üzere Fisher hipotezinin geçerli olduğu durumlarda reel faiz oranının durağan olması gerekmektedir. $\mathrm{Bu}$ amaçla, 2 numaralı denklem yardımıyla nominal faiz ve enflasyon oranlarından elde edilmiş olan reel faiz değişkenine uygulanan Fourier KPSS birim kök testine ait sonuçlar aşağıdaki gibidir:

Tablo 3: Reel Faiz Değişkenine Uygulanan Fourier KPSS Birim Kök Testinin Sonuçları

\begin{tabular}{ccccc}
\hline Değişken & Min KKT & $\mathbf{k}$ & $\begin{array}{c}\text { Fourier KPSS Test } \\
\text { İstatistiği }\end{array}$ & F istatistiği \\
\hline REELFAİZ & 18851.81 & 1 & $0.153773(12)$ & 109.5872 \\
\hline
\end{tabular}

Not: Parantez içerisindeki değer bant genişliğini ifade etmektedir. \%5 anlamlılık düzeyinde kritik değer Fourier KPSS birim kök testi için 0.1696, F testi için ise 4.651 olarak belirlenmiştir.

Tablo 3'te görüldüğü üzere reel faiz değişkenine düzeyde Fourier KPSS testi uygulanmış, hesaplanan test istatistiği kritik değerden küçük olduğu için değişkenin durağan olduğunu ifade eden temel hipotez reddedilememiştir. Trigonometrik terimlerin anlamlılı̆̆ını sınamak amaciyla $\mathrm{F}$ testi uygulanmış, $\mathrm{F}$ istatistiğinin kritik değerden büyük olduğu görülmüş ve terimlerin anlamlı olduğu anlaşılmıştır. Şekil 3 'te görüldüğg̈ üzere Fourier fonksiyonunun reel faiz değişkeni ile oldukça uyumlu olduğu dikkat çekmektedir. 


\section{Şekil 3: Reel Faiz Oranı ve Fourier Fonksiyonu}

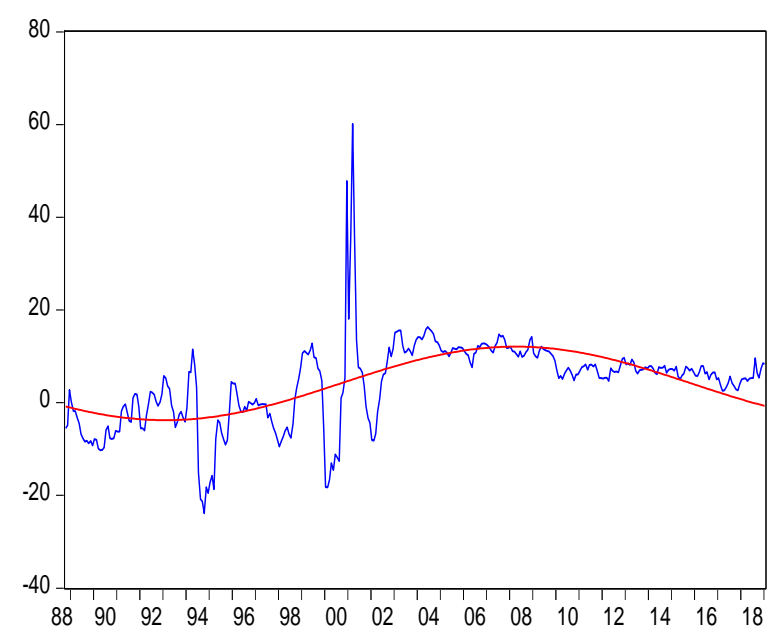

Reel faiz oranının durağan olması, nominal faiz ve enflasyon oranları arasındaki uzun dönemli ilişkiyi sınamak amacıyla uygulanan Fourier Shin eşbütünleşme testine ait sonuçları desteklemektedir. Elde edilen bulgular, Türkiye'de 1988:10-2019:01 döneminde Fisher hipotezinin geçerli olduğunu göstermektedir.

\section{Sonuç}

Bu çalışmada, Türkiye'de 1988:10-2019:01 döneminde Fisher hipotezinin geçerliliği Fourier yaklaşımı ile analiz edilmiştir. Bu amaçla, nominal faiz ve enflasyon oranlarına Fourier KPSS birim kök testi uygulanmış, değişkenlerin durağan olmadığı tespit edilmiştir. Düzeylerinde durağan olmayan değişkenlerin, aynı düzeyde durağan olup olmadıklarını incelemek amacıyla birinci farkları alındıktan sonra yeniden Fourier KPSS birim kök testi uygulanmış ve değişkenlerin birinci farkları alındığında durağan hale geldikleri anlaşılmıştır. Daha sonra, nominal faiz ve enflasyon oranları arasındaki uzun dönemli ilişkinin varlığını sınamak amacıyla Fourier Shin eşbütünleşme testi uygulanmış ve değişkenler arasında uzun dönemde tek yönlü ilişki olduğu görülmüştür. Buna göre, uzun dönemde enflasyon oranı nominal faiz oranını etkilerken, nominal faiz oranı enflasyon oranını etkilememektedir. Daha sonra, reel faiz oranının durağanlığını sınamak amacıyla Fourier KPSS birim kök testi uygulanmış ve değişkenin düzeyde durağan olduğu görülmüştür. Reel faiz oranının durağan olması eşbütünleşme testinden elde edilen bulguları desteklemektedir. Elde edilen sonuçlar, Türkiye'de 1988:10-2019:01 döneminde Fisher hipotezinin geçerli olduğunu kanıtlamaktadır.

Türkiye'de 2002 yılından itibaren açık, 2006 yılından itibaren de örtük enflasyon hedeflemesi uygulanmaktadır. Para politikası stratejisinde meydana gelen değişiklikler Fisher hipotezinin geçerliliğini etkilememektedir. Fisher hipotezinin geçerli olması paranın 
yansızlığını ve para politikasının uzun dönemde reel faiz oranını etkilemediğini ortaya koymaktadır. Reel faiz oranı uygulanan para politikaları tarafından değil, reel faktörler tarafından belirlenmektedir. Türkiye'de sıkı parasal ve mali duruşun olmaması enflasyona yol açmakta ve bu da nominal faiz oranının yükselmesine neden olmaktadır. Dolayısıyla TCMB'nin nominal faiz oranını düşürmek için öncelikli olarak fiyat istikrarına odaklanması gerekmektedir. İleride bu konuda yapılacak olan çalışmalarda 2002 yılından önceki ve sonraki dönemler için Fisher hipotezinin geçerliliğinin ayrı ayrı sınanması, Türkiye'de para politikası stratejisinde ortaya çıkan değişikliklerin enflasyon ve faiz oranları arasındaki ilişki üzerindeki etkilerine 1 şı tutabilir.

\section{Kaynakça}

Akıncı, M. ve Yılmaz, Ö. (2016). Enflasyon-faiz oranı takası: Fisher hipotezi bağlamında Türkiye ekonomisi için dinamik en küçük kareler yöntemi. Sosyoekonomi, 24(27), 33 55.

Alper, F. Ö. (2017). Türkiye'deki enflasyon ve nominal faiz oranı ilişkisinin analizi: BayerHanck eşbütünleşme testi. 3. International Congress on Politic, Economic and Social Studies (ss. 101-111).

Arısoy, İ. (2013). Testing for Fisher hypothesis under regime shifts in Turkey: new evidence from time-varying parameters. International Journal of Economics and Financial Issues, 3(2), 496-502.

Atgür, M. ve Altay O. N. (2015). Enflasyon ve nominal faiz oranı ilişkisi: Türkiye örneği (20042013). Yönetim ve Ekonomi Dergisi, 22(2), 521-533.

Banerjee, P., Arcabic, V. ve Lee, H. (2017). Fourier ADL cointegration test to approximate smooth breaks with new evidence from crude oil market. Economic Modelling, 67(C), 114- 124.

Başar, S. ve Karakuş, K. (2017). Fisher hipotezi: Türkiye için tahmini. Uluslararası Sosyal Araştırmalar Dergisi, 10(54), 794-803.

Bayat, T. (2011). Türkiye'de Fisher etkisinin geçerliliği: doğrusal olmayan eşbütünleşme yaklaşımı. Erciyes Üniversitesi İIBF Dergisi, (38), 47-60.

Becker, R., Enders, W. ve Lee, J. (2006). A stationairy test in the presence of an unknown number of smooth breaks. Journal of Time Series Analysis, 27(3), 381-409. 
Bezanic, M. (2013). Testing the Fisher effect in Croatia: an empirical investigation. Economic Research Ekonomska Istrazivanja, 26(1), 83-102.

Bolatoğlu, N. (2006). Türkiye'de enflasyon ve nominal faiz oranları arasındaki uzun dönemli ilişki: Fisher etkisi. Hacettepe Üniversitesi İ̈BF Dergisi, 24(2), 1-15.

Bozoklu, Ş. ve Yılancı, V. (2011). Fisher Hipotezi’nin gelişmekte olan ülkelerde geçerliliğinin testi. Prof. Dr. Sadık Kırbaş'a Armă̆an Kitabı (ss. 51-62), İstanbul: Okan Üniversitesi Yayınları.

Büberkökü, Ö. (2014). Yükselen piyasa ekonomilerinde nominal faiz oranları ile enflasyon arasındaki ilişkinin incelenmesi: panel koentegrasyon testlerinden kanıtlar. Bankacılar Dergisi, 25(88), 80-90.

Christopoulos, D. ve Leon-Ledesma, M. A. (2010). Smooth breaks and non-linear mean reversion: Post-Bretton Woods real exchange rates. Journal of International Money and Finance, 29(6), 1076-1093.

Christopoulos, D. ve Leon-Ledesma, M. A. (2011). International output convergence, breaks, and asymmetric adjustment', Studies in Nonlinear Dynamics and Econometrics, 15(3), $67-97$.

Çakmak, E., Aksu, H. ve Başar, S. (2002). Fisher Hipotezi'nin Türkiye açısından değerlendirilmesi: 1989-2001. Atatürk Üniversitesi Íktisadi ve İdari Bilimler Dergisi, 16(3-4), 31-40.

Çinko, L. (2017). Türkiye'de Fisher hipotezinin geçerliliğinin sınanması. Sosyal Bilimler Araştırma Dergisi, 6(1), 53-64.

Destek, M. A. ve Okumuş, İ. (2016). Satın alma gücü paritesi hipotezi geçerliliğinin Fourier birim kök testleri ile incelenmesi: OECD ülkeleri örneği”, Gaziantep University Journal of Social Sciences, 15(1), 73-87.

Doğan, B., Eroğlu, Ö. ve Değer, O. (2016). Enflasyon ve faiz oranı arasındaki nedensellik ilişkisi: Türkiye örneği. Çankırı Karatekin Üniversitesi İIBF Dergisi, 6(1), 405-425.

Doğan, İ., Afsal, M. Ş. ve Örün, E. (2018). Türkiye'de Fisher etkisi bağlamında enflasyon ve faiz oranı arasındaki ilişkinin non-parametrik analizi. Uluslararası Ekonomi Araştırmaları ve Finansal Piyasalar Kongresi Bildiri Kitabı (ss. 165-177). Ankara: Detay Yayıncilik. 
Dutt, S. ve Ghosh, D. (2005). A threshold cointegration test of the Fisher hypothesis: case study of 5 European nations. Southwestern Economic Review, 41-50.

Enders, W. ve Lee, J. (2012). The flexible Fourier form and Dickey-Fuller type unit root tests. Economics Letters, 117(1), 196-199.

Fisher, I. (1930). The theory of interest, New York: The Macmillan Company.

Gazel, S. (2018). Değerli metaller ve makroekonomik değişkenler: Türkiye için bir Fourier eşbütünleşme testi. Yönetim ve Ekonomi, 25(2), 527-542.

Granville, B. ve Mallick, S. (2004). Fisher hypothesis: UK evidence over a century. Applied Economics Letters, 11(2), 87-90.

Güriş, S., Güriş, B. ve Ün, T. (2016). Interest rates, Fisher effect and economic development in Turkey, 1989-2011. Revista Galega de Economia 25(2), 95-100.

Hasan, H. (1999). Fisher effect in Pakistan. The Pakistan Development Review, 68(1), 153-156.

Ito, T. (2009). Fisher hypothesis in Japan: analysis of long-term interest rates under different monetary policy regimes. The World Economy, 32(7), 1019-1035.

Ito, T. (2016). Does the Fisher hypothesis hold in Sweden? An analysis of long-term interest rates under the regime of inflation targeting. Review of Integrative Business and Economics Research, 5(3), 283-295.

İncekara, A., Demez, S. ve Ustaoğlu, M. (2012). Validity of Fisher effect for Turkish economy: cointegration analysis. Procedia-Social and Behavioral Sciences, 58(12), 396-405.

Jareno, F. ve Tolentino, M. (2013). The Fisher effect: a comparative analysis in Europe”, Jökull Journal, 63(12), 201-212.

Kanca, O. C, Üzümcü, A. ve Deniz, A. (2015). Fisher etkisi Türkiye ekonomisi için geçerli mi? Bir zaman serisi analizi: 1980-2013. Verimlilik Dergisi, O(3), 45-65.

Kim, D., Lin, S., Hsieh, J. ve Suen, Y. (2016). The Fisher equation: a nonlinear panel data approach. Emerging Markets Finance and Trade, 54(1), 162-180.

Köksel, B. ve Destek, M. A. (2015). Türkiye ekonomisinde Fisher hipotezinin test edilmesi: 2002-2014 dönemi üzerine bir ampirik analiz. Uluslararası Sosyal Araştırmalar Dergisi, 8(41), 1247-1253.

Küçükaksoy, İ. ve Akalın, G. (2017). Fisher Hipotezi’nin panel veri analizi ile test edilmesi: OECD ülkeleri uygulamas1. Hacettepe Üniversitesi IIIBF Dergisi, 35(1), 19-40. 
Lebe, F. ve Özalp, L. F. A. (2016). Fisher Hipotezi'nin alternatif faiz oranları ile Türkiye ekonomisi açısından analizi. Dokuz Eylül Üniversitesi İIBF Dergisi, 31(1), 95-122.

Mike, F. ve Kizılkaya, O. (2019). Testing the theory of PPP for emerging market economies that practice flexible exchange rate regimes. Applied Economic Letters, 26(17), 14111417.

Mercan, M. (2013). Enflasyon ve nominal faiz oranları arasındaki uzun dönem ilişkinin Fisher hipotezi çerçevesinde test edilmesi: Türkiye örneği. Atatürk Üniversitesi İktisadi ve İdari Bilimler Dergisi, 27(4), 368-384.

Nusair, S. A. (2008). Testing for the Fisher hypothesis under regime shifts: an application to Asian countries. International Economic Journal, 22(2), 273-284.

Omay, T. (2015). Fractional frequency flexible Fourier form to approximate smooth breaks in unit root testing”, Economics Letters, 134(C), 123-126.

Öruç, E. (2016). Fisher etkisi: Türkiye üzerine bir uygulama. Kastamonu Üniversitesi İ̈BF Dergisi, (13), 297-311.

Pınar, A. ve Erdal, B. (2018). Enflasyon hedeflemesi rejiminde Fisher etkisinin geçerliliği: Türkiye'den ampirik sonuçlar. Eskişehir Osmangazi Üniversitesi İ̈BF Dergisi, 13(3), $1-12$

Songur, M. (2018). Fisher hipotezinin Türkiye'de geçerliliği: Fourier yaklaşımı”, International Social Sciences and Education Conference, Diyarbakır.

Sağlam, Y. (2018). Fisher Hipotezi'nin Fourier yaklaşımı ile testi: Gelecek-11 ülke grubu örneği. Journal of Yaşar University, 13(52), 316-321.

Şimşek, M. ve Kadılar, C. (2006). Fisher etkisinin Türkiye verileri ile testi. Doğuş Üniversitesi Dergisi, 7(1), 99-111.

Taşar, İ., Aççı, Y. ve Bayat, T. (2016). Türkiye'de Fisher etkisinin geçerliliği asimetrik nedensellik ilişkisi ile incelenmesi. International Congress on Political, Economic and Social Studies, İstanbul.

Tiraşoğlu, M. (2018). Fisher hipotezinin MINT ülkeleri için incelenmesi: eşik değerli ADL eşbütünleşme testi yaklaşımı. Ekonometri ve İstatistik e-Dergisi, 14(28), 31-43.

Toyoshima, Y. ve Hamori, S. (2011). Panel cointegration analysis of the Fisher effect: evidence from the US, the UK, and Japan. Economics Bulletin, 31(3), 2674-2682. 
Tsong, C. C., Lee, C. F., Tsai, L. J. ve Hu, T. C. (2016). The Fourier approximation and testing for the null of Cointegration. Empirical Economics, 51(3), 1085-1113.

Tunal1, H. ve Erönal, Y. Y. (2016). Enflasyon ve faiz oranı ilişkisi, Türkiye'de Fisher etkisinin geçerliliği. Süleyman Demirel Üniversitesi İ̈BF Dergisi, 21(4), 1415-1431.

Turgutlu, E. (2004). Fisher hipotezinin tutarlılığının testi: parçalı durağanlık ve parçalı koentegrasyon analizi. Dokuz Eylül Üniversitesi İ̈BF Dergisi, 19(2), 55-74.

Yılanc1, V. (2009). Fisher hipotezinin Türkiye için sınanması: doğrusal olmayan eşbütünleşme analizi. Atatürk Üniversitesi İktisadi ve İdari Bilimler Dergisi, 23(4), 205-213.

Yılancı, V. (2017). Petrol Fiyatları ve ekonomik büyüme arasındaki ilişkinin incelenmesi: Fourier yaklaşımı. Ekonometri ve Istatistik e-Dergisi, (27), 51-67.

https://www.imf.org/en/data (Erişim Tarihi: 28.03.2019). 